\title{
KINERJA PERAWAT DALAM MELAKSANAKAN ASUHAN KEPERAWATAN DI RUANG UGD RUMAH SAKIT NASIONAL GUIDO VALADARES DILI, TIMOR-LESTE
}

\author{
Oleh: \\ Remigio Julio De Jesus Araujo Tilman ${ }^{1)}$ \\ Maria Fatimah W.A. Fouk ${ }^{2)}$ \\ Elfrida Dana Riwoe Rohi ${ }^{3)}$
}

${ }^{1), 233)}$ Prodi Keperawatan Universitas Timor Kampus Atambua, Jln-Wehor Kabuna Haliwen Atambua, Nusa Tenggara Timur. Post: 85711. Email akperbelu@ gmail.com

Kinerja Perawat sangat perlu diperhatikan oleh seorang perawat karena kinerja perawat merupakan ukuran keberhasilan dalam mencapai tujuan pelayanan keperawatan. Tujuan dari penelitian ini untuk mengetahui dan mengobservasi kinerja perawat dalam melaksanakan asuhan keperawatan di Ruang UGD Rumah Sakit Nasional Guido Valadares Dili, Timor-Leste dan penelitian ini menggunakan pendekatan kuantitatif dengan metode deskriptif murni. Sampel dalam penelitian sebanyak 32 responden, alat pengumpulan data adalah kuesioner. Hasil penelitian menunjukan bahwa rata rata usia perawat berumur 20-40 tahun yaitu sebanyak (84\%), Jenis kelamin dalam penelitian ini didapatkan paling banyak laki-laki yaitu sebanyak (59\%), Tingkat pendidikan paling banyak S.Kep yaitu sebanyak (43\%), Status Perkawinan paling banyak menikah yaitu sebanyak (66 \%) dan Lama kerja paling banyak 11-25 tahun yaitu sebanyak $(53 \%)$. sedangkan kinerja perawat yang memiliki kinerja baik yaitu sebanyak $(53 \%)$,dan perawat yang memiliki kinerja yang buruk yaitu sebanyak (47\%). Dari hasil penelitian diatas maka disimpulkan bahwa kinerja perawat dalam melakukan asuhan keperawatan di UGD Rumah Sakit Nasional Guido Valadares sudah masuk dalam kategori baik. Oleh karena itu diharapkan dapat mempertahankan dan meningkatkan kinerja perawat dengan baik sehingga bisa meningkatkan mutu pelayanan yang profesional.

Kata Kunci : Kinerja prawat, Asuhan keperawatan.

\section{DESCRIPTION OF NURSE'S PERFORMANCE IN IMPLEMETING NURSING CARE IN EMERGENCY ROOM UNIT AT NATIONAL HOSPITAL OF GUIDO VALADARES DILI, TIMOR- LESTE.}

\author{
By: \\ Remigio Julio De Jesus Araujo Tilman ${ }^{1)}$ \\ Maria Fatimah W.A. Fouk ${ }^{2)}$ \\ Elfrida Dana Riwoe Rohi ${ }^{3}$
}

1),2)3) Nursing Program at University of Timot campus Atambua, Street-Wehor Kabuna Haliwen

Atambua, East Nusa Tenggara. Post 85711 Email: akperbelu@ gmail.com

The performance of nurse's is highly regarged by a nurse because the performance of the nurse is a measure of success in achieving the goal of nursing service. The purpose of this research is to know and to observe the performance of nurses in performing nursing care in The National Hospital Emergency Room Unit of Guido Valadares Dili, Timor Leste and this research using quantitative approach with pure descriptive method. The sample in this study as many as 32 respondents, data collection tool is a questionnaire. The result showed that the avarage age of nurses aged 20-40 years is as many ( $84 \%)$, sex in this research obtained the most men are many (59\%), level of education at most S.kep taht is as much (43\%), married status at most marriage that is as much $(66 \%)$ and duration of work at mort 11-25 years that is as much $(53 \%)$. While the 
performance of nurses who have good performance are as many as (53\%), and nurses who have poor performance that is as much (47\%). From the result of the above research it is concluded that the performance of nurses in performing nursing care at the Hospital Emergency Unit National Guido Valadares already entered in good category. Therefore it expected to maintain and improve the performance of nurse properly so as to improve the quality of profesional services.

Keywords : Nurse Performance, Nursing care.

\section{Latar Belakang}

Instalasi Gawat Darurat (IGD) merupakan suatu organisasi pelayanan kesehatan di rumah sakit yang bertujuan memberikan pelayanan kegawat daruratan pertama selama 24 jam pada pasien dengan ancaman kematian dan kecacatan secara terpadu dengan melibatkan multidisiplin ilmu. (Depkes RI, 2011). Dengan kata lain IGD sebagai "Gateway" antara pasien dengan rumah sakit guna mendapat pelayanan kegawatdaruratan sekaligus merupakan garda depan kualitas pelayanan kesehatan rumah sakit, artinya baik atau buruknya pelayanan di IGD dapat menggambarkan keseluruhan kualitas pelayanan rumah sakit (Ningsih, 2015 dalam Fouk, 2016).

Konsep dasar gawat darurat merupakan suatu hal yang sangat penting untuk dipahami oleh semua profesi kesehatan termasuk awam ataupun awam khusus. Dalam kondisi gawat darurat, tiga hal yang kritis adalah pertama kecepatan waktu pertama korban ditemukan, kedua ketepatan dan akurasi pertolongan oleh petugas kesehatan yang kompeten. Statistik membuktikan bahwa hampir 90\% korban meninggal atau cacat disebabkan oleh korban terlalu lama dibiarkan atau waktu ditemukan telah melewati The Gold Time dan ketidaktepatan serta akurasi pertolongan pertama saat pertama kali korban ditemukan. Rentang gawat darurat dapat dibedakan menjadi tiga yaitu: Pre-Hospital, In-Hospital dan PostHospital. Keadaan darurat di komunitas biasanya lebih kompleks dibangding kejadian gawat darurat di rumah sakit. (Sudiharto dan Sartono, 2011).

Perawat sebagai salah satu sumber daya manusia yang 
memiliki peran penting dalam memberikan asuhan keperawatan kegawatdaruratan di IGD karena sebagai ujung tombak dan merupakan tenaga yang paling lama berinteraksi dengan pasien yakni selama 24 jam. (Santoso, dkk 2003). Teori ini sesuai dengan Nursalam (2014) menjelaskan bahwa perawat sebagai salah satu komponen sumber daya manusia dalam organisasi pelayanan keperawatan di rumah sakit memiliki kemampuan/kealihan dan latar belakang (pengalaman, pendidikan, lama kerja ) yang dapat dipertimbangkan sebagai salah satu indikator penilaian kinerja.

Kinerja atau performance adalah efforts (upaya atau aktivitas) ditambah achievements (hasil kerja atau pencapaian hasil upaya). (Suprianto dan Ratna 2007 dalam Nursalam, 2014). Gambaran kinerja dalam melaksanakan kegiatan merupakan seperangkat fungsi, tugas dan tanggung jawab hal ini merupakan dasar utama perawat untuk memahami dengan tepat fungsi, tugas dan tanggung jawabnya. ( Mulati, 2006).

Pelayanan keperawatan diberikan dalam bentuk kinerja perawat harus didasari kemampuan yang tinggi dalam membentuk sehingga kinerja mendukung pelaksanaan tugas dalam pelayanan keperawatan. (Siahaan dan Tarigan, 2010).

Kinerja Perawat merupakan apliksasi kemampuan atau pembelajaran yang telah diterimah selama menyelesaikan program pendidikan keperawatan untuk memberikan pelayanan dan bertanggung jawab dalam peningkatan kesehatan dan pencegahan penyakit serta pelayanan terhadap pasien. (Ali 2002 dan Mulati, 2006).

Masalah utama kinerja perawat dalam pelayanan keperawatan adalah kurangnya perawat yang berpendidikan tinggi, kemauan yang tidak memadai, banyaknya perawat yang kasar (kurang ramah terhadap pasien) kurang sabar dalam menghadapi pasien masalahnya itu tentu bukan hanya soal sikap ramah atau penyabar, tetapi juga beban kinerja 
yang tinggi, peraturan yang belum jelas kepada perawat. (Adimata, 2003).

Penilaian kinerja merupakan alat yang paling dapat dipercaya oleh manajer perawat dalam mengontrol sumber daya manusia dan produktivitas (Swanburg, 1987 dalam Nursalam, 2007). Proses penilaian kinerja dapat digunakan secara efektif dalam mengarahkan perilaku pegawai, dalam rangka menghasilkan jasa keperawatan dalam kualitas dan volume yang tinggi, perawat manajer dapat menggunakan proses operasional kinerja untuk mengatur arah kerja dalam memilih, melatih, membinbing perencanaan pasien, serta memberi penghargaan kepada perawat yang berkompeten. (Nursalam, 2007).

Hasil Penelurusan Gustinerz dari data base online (SIMK PERAWAT) jumlah perawat di indonesia per 22 oktober 2017 adalah sebanyak 384.946 orang ( perawat yang telah terintegrasi di PPNI secara online/memiliki NIRA). Dari beberapa Rumah sakit di Indonesia, rata-rata jumlah tenaga perawat dibanding dengan pasien tidak seimbang. Karena pemerintah membandingkan perawat dengan jumlah tempat tidur, bukan berdasarkan pasien. Banyaknya pasien yang masuk mengharuskan Rumah Sakit memiliki perawat yang berkualitas dan berdedikasi tinggi sehingga diharapkan memiliki kinerja yang baik. Data keterangan yang diambil pada suatu Rumah Sakit di kota Surakarta pada tahun 2009 adalah S1 : 102 Perawat, D3 : 381 Perawat, dan SPK : 10 perawat. Dengan Demikian jumlah tenaga perawat ada 493 perawat. Hasil pendataan yang dilakukan di catatan medik selama 2009 didapatkan jumlah pasien masuk sebanyak 174.803 pasien. Jumlah kapasitas tempat tidur 704 bed dan jumlah rata rata nilai BOR (Bed occupancy Rate) yaitu 66,65 \% (Rekam Medik RSUD Dr. Moewardi Surakarta, 2010).

Berdasarkan hasil wawancara dengan salah satu perawat di Ruang Instalasi Gawat Darurat di Rumah Sakit Nasional Guido Valadares Dili, Timor Leste jumlah perawat di ruang IGD sebanyak 35 orang termasuk kepala ruagan dan ketua tim. Dari 35 perawat dibagi menjadi 4 tim, dengan latar belakang 
bervariasi yakni 1 orang S.Kep NS, 14 orang S.Kep, 10 orang Amd.Kep, 8 orang SPK dan 7 orang asisten perawat. Sebanyak jumlah kunjungan rata rata 150 pasien perhari. Hal ini tidak sebanding dengan jumlah perawat yang bertugas tim yakni hanya 9-12 perawat per har, 3-4 perawat setiap. Dengan demikian beban kerja perawat tinggi yang akan berdampak pada penerapan asuhan keperawatan gawat darurat.

Asuhan keperawatan gawat darurat merupakan salah satu indikator penilaian kinerja perawat sekaligus sebagai indikator mutu pelayanan keperawatan ( Nursalam, 2015 ).

Berdasarkan uraian di atas maka penulis tertarik untuk melakukan penelitian dengan judul Gambaran Kinerja perawat dalam melaksanakan Asuhan Keperawatan di Ruang Unit Gawat Darurat di Rumah Sakit Nasional Guido Valadares Dili, Timor-Leste. Tujuan dari penelitian ini adalah mengidentifikasi kinerja perawat dalam melaksanakan asuhan keperawatan di Instalasi Gawat Darurat Rumah Sakit Nasional Guido Valadares Dili, Timor Leste

\section{Metodologi}

Desain penilitian dalam penelitian ini penulis menggunakan pendeketan kuantitatif deskriptif dengan pendekatan cros sectional dengan tujuan untuk mendeskripsikan penilaian kinerja perawat dalam melaksanakan asuhan keperawatan di Rumah Sakit Nasional Guido valadaes. Jumlah sampel pada penelitian ini adalah 35 perawat UGD RSN Guido Valadares Dili yang dipilih dengan teknik kuota sampling dimana ketika peneliti sudah mendapatkan responden sebanyak 35 orang, maka pengumpulan data penelitian berakhir.

Adapun kriteria inklusi dalam penelitian ini adalah 1) perawat yang bersedia menjadi responden, dan 2) perawat yang bertugas di ruang instalasi gawat darurat RS Nasional Guido Valadares Dili, Timor Leste.

Untuk menjawab etika penelitian, peneliti menjelaskan tujuan dan manfaat dari penelitian kepada responden. Selanjutnya perawat yang bersedia menjadi responden membubuhi tandatangan pada lembar 
persetujuan yang telah disediakan.

Selain itu peneliti juga menyadari bahwa penelitian ini tidak tidak menimbulkan resiko cedera kepada responden. Persetujuan ijin penelitian juga telah diperoleh dari institusi pendidikan, dan Direktur Rumah Sakit Nasional Guido Valadares Dili, Timor Leste. Peneliti tetap menjaga kerahasiaan responden dimana responden tidak perlu menuliskan nama pada kuisioner. Peneliti melakukan pengambilan data dengan cara menyebarkan kuisioner kepada responden. Adapun kuisioner tersebut berisi tentang kinerja perawat yang meliputi: Pengkajian, perencanaan, implementasi, evaluasi dan ketrampilan komunikasi. Analisis yang digunakan dalam penilitian ini adalah dengan menggunkan analisa univariat yaitu mengidentifikasi distribusi frekuensi tiap variabel. Selanjutnya hasil untuk mengukur kinerja perawat dalam melaksanakan asuhan keperawatan yaitu berdasarkan Depkes RI, 2007 standar pencapaian kinerja dalam pemberian asuhan keperawatan minimal $75 \%$. Dengan demikian kriteria penilaian dikatakan kinerja baik jika nilai $>75 \%$ dan buruk jika nilai < $75 \%$. Hasil penelitian ditampilkan dalam bentuk tabel dan diinterpretasikan secara deskriptif.

\section{Hasil}

Tabel 1 menunjukkan bahwa umur responden yang paling banyak di Ruang UGD di Rumah Sakit Nasional Guido Valadares yaitu 20-40 tahun yakni sebanyak 20 orang $(63 \%)$. Jumlah respoden berdasarkan jenis kelamin paling banyak Laki-Laki yaitu sebanyak 19 responden (59\%). Jumlah responden berdasarkan tingkat pendidikan paling banyak yaitu S.Kep Yaitu sebanyak 14 responden (43\%). Jumlah responden berdasarkan status perkawinan paling banyak menikah yaitu sebanyak 21 responden (66 \%). Jumlah responden berdasarkan lama kerja yaitu 10-25 sebanyak 17 responden (53\%) 
Tabel 1

Distribusi Karakteristik responden berdasarkan umur, tingkat pendidikan, jenis kelamin, lama kerja dan status perkawinan di UGD Rumah Sakit Nasional Guido Valadares Bulan Mei 2018 (N=32)

\begin{tabular}{|c|c|c|c|c|c|}
\hline NO & Variabel & Klasifikasi & $\begin{array}{l}\text { Frekuens } \\
\text { i (N) }\end{array}$ & $\begin{array}{c}\text { Persentase } \\
(\%)\end{array}$ & Total \\
\hline & & 1. 20-40 tahun & 27 & 84 & \\
\hline 1. & Umur & 2. $41-56$ tahun & 5 & 16 & 100 \\
\hline \multirow[t]{2}{*}{2.} & Jenis & 1. Perempuan & 13 & 41 & \multirow[t]{2}{*}{100} \\
\hline & Kelamin & 2. Laki-Laki & 19 & 59 & \\
\hline \multirow{4}{*}{3.} & & $1 \mathrm{SPK}$ & 7 & 21 & \multirow{4}{*}{100} \\
\hline & Tingkat & $2 \mathrm{D} 3$ & 10 & 32 & \\
\hline & Pendidikan & 3 S.Kep & 14 & 43 & \\
\hline & & 4 S.Kep:Ns & 1 & 3 & \\
\hline \multirow{3}{*}{4.} & & 1. Menikah & 21 & 66 & \multirow{3}{*}{100} \\
\hline & Status & 2. Belum & 11 & 34 & \\
\hline & Perkawian & Menikah & & & \\
\hline \multirow{3}{*}{5} & \multirow{3}{*}{ Lama Kerja } & 1. 1-10 Tahun & 15 & 47 & \multirow{3}{*}{100} \\
\hline & & 2. 11-25 Tahun & & & \\
\hline & & & 17 & 53 & \\
\hline
\end{tabular}

Tabel 2 menunjukan bahwa sebagian besar perawat mempunyai kinerja yang baik dalam melaksanakan pengkajian di Ruang UGD Di Rumah Sakit Nasional Guido Valadares yaitu sebanyak 17 responden (53\%) dan responden yang mempunyai kinerja buruk yaitu 15 responde (47\%)

Tabel 2

Distribusi frekuensi responden berdasarkan kinerja perawat dalam melaksanakan Pengkajian di Ruang Unit Gawat Darurat di Rumah Sakit Nasional Guido Valadares Bulan Mei $2018(n=32)$

\begin{tabular}{|c|c|c|c|}
\hline Variabel & Kategori & Frekuensi (n) & Persentase (\%) \\
\hline \multirow{2}{*}{$\begin{array}{c}\text { Kinerja perawat dalam } \\
\text { melaksanakan Pengkajian }\end{array}$} & Baik & 17 & 53 \\
\cline { 2 - 4 } & Buruk & 15 & 47 \\
\hline \multicolumn{2}{|c|}{ Total } & 32 & 100 \\
\hline
\end{tabular}


. Tabel 3 menunjukan bahwa sebagian besar perawat mempunyai kinerja yang buruk dalam Merumuskan Diagnosa Keperawatan di Ruang UGD Di Rumah Sakit Nasional Guido Valadares yaitu sebanyak 18 responden (56 \%) dan responden yang mempunyai kinerja yang baik yaitu sebanyak 14 responden (44 $\%)$

Tabel 3

Distribusi frekuensi responden berdasarkan kinerja perawat dalam merumuskan Diagnosa keperawatan di Ruang Unit Gawat Darurat di Rumah Sakit Nasional Guido Valadares Bulan Mei 2018 (n=32)

\begin{tabular}{cccc}
\hline Variabel & Kategori & Frekuensi (n) & Persentase (\%) \\
\hline $\begin{array}{c}\text { Kinerja perawat } \\
\text { dalam merumuskan } \\
\begin{array}{c}\text { diagnosa } \\
\text { keperawatan }\end{array}\end{array}$ & Baik & 14 & 44 \\
\cline { 2 - 4 } & Buruk & 18 & 56 \\
\cline { 2 - 4 } & Total & 32 & 100 \\
\hline
\end{tabular}

Tabel 4 menunjukan bahwa sebagian besar perawat mempunyai kinerja yang baik dalam menyusun Perencanaan di Ruang UGD Di Rumah Sakit Nasional Guido Valadares yaitu sebanyak 21 responden $(66 \%)$ dan responden yang mempunyai kinerja buruk yaitu sebanyak 11 responden (34\%).

\section{Tabel 4}

Distribusi frekuensi responden berdasarkan kinerja perawat dalam menyusun perencanaan di Ruang Unit Gawat Darurat di Rumah Sakit Nasional Guido Valadares Bulan Mei $2018(n=32)$.

\begin{tabular}{cccc}
\hline Variabel & Kategori & Frekuensi (n) & Persentase(\%) \\
\hline \multirow{2}{*}{$\begin{array}{c}\text { Kinerja Perawat } \\
\text { (Perencanaan) }\end{array}$} & Baik & 21 & 66 \\
\cline { 2 - 4 } & Buruk & 11 & 34 \\
\hline
\end{tabular}


Tabel 5 menunjukan bahwa sebagian besar perawat mempunyai kinerja yang baik dalam Implemetasi keperawatan di Ruang UGD Di Rumah Sakit Nasional Guido Valadares yaitu sebanyak 22 responden (69\%) dan responden yang mempunyai kinerja buruk yaitu sebanyak $10(31 \%)$

Tabel 5

Distribusi frekuensi responden berdasarkan kinerja perawat dalam implementasi keperawatan di Ruang Unit Gawat Darurat di Rumah Sakit Nasional Guido Valadares Bulan Mei $2018(\mathbf{n = 3 2})$

\begin{tabular}{cccc}
\hline Variabel & Kategori & Frekuensi (n) & Persentase (\%) \\
\hline \multirow{2}{*}{$\begin{array}{c}\text { Kinerja Perawat } \\
\text { (Implementasi) }\end{array}$} & Baik & 22 & 69 \\
\cline { 2 - 4 } & Buruk & 10 & 31 \\
\hline
\end{tabular}

Tabel 6 menunjukan bahwa sebagian besar perawat mempunyai kinerja yang baik dalam evaluasi di Ruang UGD Di Rumah Sakit Nasional Guido Valadares yaitu sebanyak 20 responden $(62,5)$ dan responden yang mempunyai kinerja buruk yaitu 12 responden $(37,5 \%)$

Tabel 6

Distribusi frekuensi responden berdasarkan kinerja perawat dalam evaluasi di Ruang Unit Gawat Darurat di Rumah Sakit Nasional Guido Valadares Bulan Mei $2018(n=32)$

\begin{tabular}{cccc}
\hline Variabel & Kategori & Frekuensi (n) & Persentase (\%) \\
\hline \multirow{2}{*}{$\begin{array}{c}\text { Kinerja Perawat } \\
\text { (Evaluasi) }\end{array}$} & Baik & 20 & 62,5 \\
\cline { 2 - 4 } & Buruk & 12 & 37,5 \\
\hline
\end{tabular}


Tabel 7 menunjukan bahwa sebagian besar perawat mempunyai kinerja yang baik dalam keterampilan komunikasi di Ruang UGD Di Rumah Sakit Nasional Guido Valadares yaitu sebanyak 19 responden (59\%) dan responden yang mempunyai kinerja yang buruk yaitu sebanyak 13 responden (41\%)

Tabel 7

Distribusi frekuensi responden berdasarkan kinerja perawat dalam Keterampilan Komunikasi di Ruang Unit Gawat Darurat di Rumah Sakit Nasional Guido Valadares Bulan Mei $2018(n=32)$

\begin{tabular}{cccc}
\hline Variabel & Kategori & Frekuensi (n) & Persentase (\%) \\
\hline $\begin{array}{c}\text { Kinerja Perawat } \\
\text { (Keterampilan } \\
\text { Komunikasi) }\end{array}$ & Baik & 19 & 59 \\
\cline { 2 - 4 } & Botal & 13 & 41 \\
\hline
\end{tabular}

Tabel 8 menunjukan bahwa sebagian besar responden mempunyai kinerja yang baik yaitu sebanyak 17 (53\%), dan responden yang mempunyai kinerja yang buruk yaitu sebanyak 15 responden (47)

Tabel 8

Distribusi Frekuensi responden berdasarkan Kinerja Perawat di Ruang UGD di Rumah Sakit Nasional Guido Valadares Dili- Timor Leste Bulan mei $2018(n=32)$

\begin{tabular}{cccc}
\hline Variabel & Kategori & Frekuensi (n) & Presentase (\%) \\
\hline \multirow{2}{*}{$\begin{array}{c}\text { Kinerja Perawat } \\
\text { Dalam melasanakan } \\
\text { asuhan keperawatan }\end{array}$} & Baik & 17 & 53 \\
\cline { 2 - 4 } & Buruk & 15 & 47 \\
\cline { 2 - 4 } & Total & 32 & 100 \\
\hline
\end{tabular}


Pembahasan

Berdasarkan hasil uji distribusi frekuensi terhadap umur, tingkat pendidikan, jesis kelamin, lama kerja dan status perkawinan didapatkan hasil sebagai berikut : rata rata responden berumur 20-40 tahun, Jenis kelamin rata rata lakilaki yaitu sebanyak 19 responden, tingkat pendidikan rata rata D III keperawatan, status perkawinan rata rata sudah menikah, lama kerja rata rata 11-25 tahun. Hal ini didukung oleh hasil penelitian sebelumnya yang dilakukan oleh siahaan (2011). Berdasarkan penelitianya di Rumah Sakit Tk. II Putri Hijau Medan diperoleh mayoritas berpendidikan D III keperawatan dan status pernikahan mayoritas sudah menikah.

Asuhan keperawatan merupakan proses atau rangkaian kegiatan pada praktik keperawatan yang diberikan secara langsung kepada klien/pasien di berbagai tatanan pelayanan kesehatan (Ali, 2002 dalam Nursalam, 2007).

Asuhan keperawatan merupakan proses atau tahapan kegiatan dalam perawatan yang diberikan secara langsung kepada pasien dalam berbagai tatanan pelayanan kesehatan. Asuhan keperawatan dapat dilakukan atau diberikan kepada pasien sebagai rangka untuk memenuhi kebutuhan pasien yang didasarkan pada 5 kebutuhan dasar manusia menurut Abrahan Maslow.

Berdasarkan penelitian ini peneliti menemukan sebanyak 17 responden (53\%) telah melakukan pengkajian dengan baik. Hal ini tidak sebanding dengan hasil penelitian Siahaan (2011), di Rumah Sakit Tk. II Putri Hijau Medan diamana jumlah respondennya 105 responden dan yang telah melaksanakan pengkajian dengan baik yaitu sebanyak 69 responden $(66 \%)$.

Pengakajian adalah proses pengumpulan data primer dan sekunder terfokus tentang status kesehatan pasien di rumah sakit secara sistematik, akurat, dan berkesinambungan. (Depkes, 2010).

Pengkajian merupakan hal yang terpenting dalam melakukan asuhan keperawatan karena didalamnya rangkaian pengumpulan data dan 
akan mempengaruhi pekerjaan selanjutnya yaitu Diagnosa keperawatan sampai dengan evaluasi. Pengkajian pada UGD dilakukan melalui beberapa tahap yaitu:

1. Primary survey

Di primary survey akan melakukan pengkajian terhadap :Airway dan servical control, Breathing dan Ventilation, Circulation dan Hemorrhage control.

2. Secondary suvey

Di Secondary survey akan melakukan pengkajian terhadapa : Fokus Assesment dan Head to toe assesment

\section{Kinerja Perawat dalam merumuskan diagnosa keperawatan}

Berdasarkan Hasil penelitian ini yang telah melaksanakan Diagnosa keperawatan dengan buruk yaitu sebanyak 14 responden (44\%) dari 32 responden. Hal ini tidak sebangding dengan hasil penelitian sebelumnya yang dilaknsnakan oleh Siahaan (2011) berdasarkan penelitianya di Rumah Sakit Tk. II Putri Hijau Medan dimana Jumlah respondenya 105 orang dan yang melaksnakan diagnosa keperawatan dengan baik yaitu sebanyak 84 responden.

Diagnosa

keperawatan merupakan keputusan klinis Perawat tentang respon pasien terhadap masalah kesehatan aktual maupun resiko yang mengancam jiwa (Depkes, 2011).

\section{Kinerja perawat dalam menyusun perencanaan}

Berdasarkan Hasil penelitian ini juga terdapat 21 responden (66\%) yang telah menyusun perencanaan dengan baik, Hal ini didukung oleh hasil penelitian sebelumnya yang dilakukan oleh Siahaan (2011) berdasarkan penelitianya di Rumah Sakit Tk. II Putri Hijau Medan diperoleh dari jumlah responden sebanyak 105 responden dan responden yang melaksanakan perencanaan dengan baik yaitu sejumlah 73 responden (70 $\%)$.

Perencanaan merupakan serengkaian langkah yang bertujuan untuk menyelesaikan masalah diagnosa keperawatan gawat darurat berdasarkan prioritas masalah yang telah ditetapkan baik secara mandiri maupun melbatkan lembaga kesehatan lain untuk mencapai tujuan 
yang telah diterapkan. (Depkes, 2011).

\section{Kinerja Perawat dalam implementasi}

Berdasarkan hasil penelitian ini terdapat 22 responden (69 \%) yang telah melaksanakanya dengan baik. Hal ini didukung oleh hasil penelitian sebelumnya yang dilakukan oleh Siahaan (2011) berdasarkan penelitianya di Rumah Sakit Tk. II Putri Hijau Medan diperoleh dari jumlah responden sebanyak 105 responden dan responden yang telah mengimplementasikannya dengan baik yaitu sejumlah 79 responden (75\%).

Implementasi keperawatan merupakan serangkaian keiatan yang dilakukan oleh perawat untuk membantu klien dari masalah status kesehatan ke status kesehatan yang elbih baik yang menggambarkan kriteria hasil yang diharapkan, melakukan tindakan keperawatn mengacu pada standar prosedur operasional yang telah ditentukan sesuai dengan tingkat kegawatan pasien, berdasarkan prioritas tindakan. (Depkes, 2011).
Implementasi keperawatan merupakan hasil dari rencana keperawatan yang di lihat dari diagnosa keperawatan, dimana perawat membantu klien dari masalah status kesehatan yang dihadapi pasien tujuannya untuk mencapai kriteria hasil yang diharapkan.

\section{Kinerja Perawat dalam \\ Melaksanakan Evaluasi}

Berdasarkan hasil penelitian ini Evaluasi Keperawatan yang telah dilaksanakan di Ruang UGD di Rumah Sakit Nasional Guido Valadares Dili, Timor-Leste terdapat 20 responden $(62,5 \%)$ telah melasanakanya dengan baik. Hal ini didukung oleh hasil penelitian sebelumnya yang dilakukan oleh Siahaan (2011) berdasarkan hasil penelitiannya di Rumah sakit TK. II Putri Hijau Medan diperoleh dari 105 responden yang melaksanakan evaluasi dengan baik yaitu sebanyak 80 responden $(76,2 \%)$.

$$
\text { Evaluasi Merupakan }
$$

Penilaian perkembangan kondisi pasien setelah dilakukan tindakan keperawatan gawat darurat 
mengacu pada kriteria hasil. juga menggunakan tutur bahasa yang (Depkes, 2010).

\section{Evaluasi}

Keperwatan

merupakan tahap akhir dari proses keperawatan yang bertujuan untuk mengetahui hasil yang diharapkan telah tercapai atau belum. Hasil akan dicapai jika semua kegiatan proses asuhan keperawatan dari pengajian sampai evaluasi dilakukan dengan benar dan tepat.

\section{Kinerja Perawat dalam}

\section{keterampilan komunikasi}

Berdasarkan hasil penelitian ini responden yang telah melakukan keterampilan komunikasi dengan $\begin{array}{lll}\text { baik yaitu sebanyak } & 19\end{array}$ responden $(59 \%)$, berdasarkan hasil observasi peneliti terhadap salah satu perawat yang bekerja di ruang UGD Di Rumah Sakit Nasonal Guido Valadares pada saat melakukan komunikasi dengan pasien ia menggunakan tutur bahasa yang halus dan menyenagkan. Hal ini didukung oleh hasil penelitian sebelumnya yang dilakukan oleh Dhaneswari (2015) di RSU Jati Husada Karangganyar di ruang UGD ia mengatakan bahwa sebagian besar perawat di RSU Jati Karangganyar halus dan menyenankan saat berkomunikasi dengan pasien.

Komunikasi merupakan unsur yang terpenting dalam aktivitas manajer keperawatan dan sebagai bagian yang selalu ada dalam proses manajemen keperawatan bergantung pada posisi manajer dalam struktur organisasi. (swanburg, 1990 dalam Nursalam, 2007).

Komuniaksi merupakan proses penyampaian informasi oleh seseorang kepada orang lain baik dapat diterimah secara lansung maupun tidak langsung. Komunikasi merupakan proses pengiriman dan penerimaan pesan, berita, atau informasi yang terjadi diantara dua orang atau lebih.

\section{Kinerja Perawat Dalam} Melaksanakan Asuahan Keperawatan

Berdasarkan hasil penelitian didapatkan bahwa dari 32 orang responden yang mempunyai kinerja baik yaitu sebanyak 17 responden (53\%), cukup Yaitu sebanyak 9 responden (28\%) dan kurang yaitu sebanyak 6 responden (19\%). Hal ini didukung oleh hasil penelitian 
sebelumnya yang dilakukan oleh

Siahaan (2011). Berdasarkan penelitiannya di Rumah sakit TK. II Putri Hijau Medan diperoleh dari 105 responden mayoritas responden (71\%) didapatkan kinerjanya baik sedangkan yang buruk (29\%).

Kinerja atau performance adalah efforts (upaya atau aktivitas) ditambah achievements (hasil kerja atau pencapaian hasil upaya). (Suprianto dan Ratna 2007 dalam Nursalam, 2014). Kinerja Perawat merupakan apliksasi kemampuan atau pembelajaran yang telah diterimah selama menyelesaikan program pendidikan keperawatan untuk memberikan pelayanan dan bertanggung jawab dalam peningkatan kesehatan dan pencegahan penyakit serta pelayanan terhadap pasien. (Ali 2002 dalam Mulati, 2006).

Kinerja merupakan penampilan hasil kerja baik kuantitas maupun kualitas dalam suatu unit pelayanan. Kinerja perawat merupakan usaha seorang perawat dari hasil kerja yang dapat dicapai dalam suatu organisasi yang dipengaruhi oleh beberapa faktor.

\section{Kesimpulan}

Berdasarkan hasil penelitian dan pengolahan data tentang gambaran kinerja perawat dalam melakukan asuhan keperawatan di Ruang Unit Gawat Darurat Di Rumah Sakit Nasional Guido Valadares Dili, Timor-Leste dapat disimpulkan bahwa kinerja perawat di Ruang Unit Gawat Darurat Di Rumah Sakit Nasional Guido Valadares Dili, Timor-Leste dalam melaksanakan pengkajian, diagnosa keperawatan, perencanaan, implementasi, evaluasi dan keterampilan komunikasi pada pasien yaitu sebagian besar perawat memiliki kinerja yang baik yaitu sebanyak 17 responden (53\%). Hal ini menunjukan bahwa perawat yang bertugas di unit tersebut telah melakukan asuhan keperawatan dengan baik. Disarankan kepada pihak manajemen rumah sakit agar meningkatkan kinerja yang ada serta didukung dengan komunikasi terapeutik yang optimal. Sedangkan untuk peneliti selanjutnya disarankan agar mengembangkan penelitian serupa dengan melibatkan responden menjadi lebih banyak. 


\section{Referensi}

Dhaneswari 2015. Komunikasi antara perawat terhadap pasien di IGD RSU Jati Husada Karanganyar Jawa Tengah

Haryanti, dkk, 2013, Hubungan antara beban kerja dengan stres kerja perawat di instalasi gawat darurat RSUD Kabupaten Semarang.

Musliha. 2010. Keperawatan Gawat Darurat. Yogyakarta: Nuha Medika

Nursalam, M. 2007. Manajemen Keperawatan: Aplikasi Dalam Praktik Keperawatan Profesional Edisi 2. Jakarta: Salemba Medika

Nursalam. 2011. Manajemen Keperawatan: Aplikasi Dalam
Praktik Keperawatan Profesional Edisi 3. Jakarta: Salemba Medika

Nursalam. 2014. Manajemen Keperawatan: Aplikasi Dalam Praktik Keperawatan Profesional Edisi 4. Jakarta: Salemba Medika

Siahaan, Taringan. 2012. Kinerja Perawat Dalam Pemberian Asuhan Keperawatan Di Rumah Sakit TK II Putri Hijau Medan. https://jurnal.usu.ac.id

Sudiharto, Sartono. 2011. Basic Trauma Cardiac Life Suport. Jakarta: CV Sagung Seto

Suhartati, Saida, Prayetni, et all. 2011. Standar Pelayanan Keperawatan Gawat Darurat Di Rumah Sakit. 